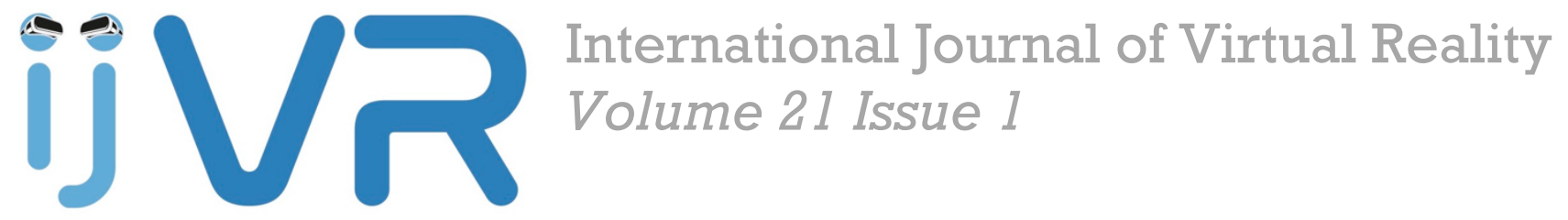

Marfisi-Schottman, I., Touel, S., \& George, S. (2021).

Designing a Mixed Reality Extension for an Educational Board Game on Fractions.

International Journal of Virtual Reality, 21(1), 47-57.

https://doi.org/10.20870/IJVR.2021.21.1.4784

CC BY 4.0 license

Published: 6/2021

ISSN: 2727-9979 


\title{
Designing a Mixed Reality Extension for an Educational Board Game on Fractions
}

\author{
Iza Marfisi-Schottman ${ }^{1}$, Sofiane Touel ${ }^{2}$, Sébastien George ${ }^{1}$ \\ ${ }^{1}$ Le Mans Université, EA 4023, LIUM, 72085 Le Mans, France \\ ${ }^{2}$ Plaisir Maths Lab, 75011 Paris, France \\ Corresponding author: Marfisi Iza, iza.marfisi@univ-lemans.fr \\ Keywords: Mixed Reality - Mathematics - Fractions - User-Centered Design
}

\begin{abstract}
Fractions are one of the most complex and challenging notions for children and can often lead to frustration and a revulsion for mathematics in general. In this article, we present the Magic Cauldron, a Mixed Reality (MR) application, designed to help children apprehend fractions in a fun and interactive way. The proposed solution is a digital extension to a board game, called the Potion Workshop that is used to introduce fractions in more than 2000 schools in France. We put together a team, composed of the mathematics didacticians who designed the Potion Workshop, several teachers who use this game in their class, a multimedia designer and computer scientists, in order to create a MR game that would tackle several of the key notions that are still hard to grasp. In this article, we present the Design-Based method followed by this team. It offers insights on how to implicate non-computer scientists in the design of complex custom MR interactions. Through several cycles of collaborative design, involving three teachers and their students and the development of three prototypes, this method allowed us to produce a truly original MR application.
\end{abstract}

\section{Fractions: a Complexe Concept to Master}

Math is an important discipline, right from the beginning of school. Studies show that succeeding in math usually implies success in reading and other disciplines (Siegler et al., 2012). Yet, many children in France dislike math and science in general (Perronnet, 2018). This aversion seems to appear, most often, in primary school, when fractions are introduced. Fractions are challenging mathematical concepts that are taught with many representations (Behr \& Post, 1993). The ultimate objective is to understand the concept of fractions as rational numbers (p divided by q), that can be placed on a number line (Gunderson et al., 2019). However, this notion is too complex for children. Fractions are therefore usually presented, at the beginning, in terms of parts of an object (e.g. parts of pizza or cake). This simplified representation helps children grasp the concept but creates several didactic obstacles. Indeed, the representation of a fraction as a part of an object may lead to misunderstanding the fact that a fraction cannot greater than one. The fact that the objects are different can also lead to a misunderstanding of fraction equivalences. Indeed, a portion of pizza and a portion of cake do not feel the same, even if the pizza and the cake have the same weight. These notions are very complex for the large majority of children, who, at the end of the third cycle in France (CM1, CM2 and $6^{\text {ème }}$, from 9 to11 years old), still have not grasped the key notions of fractions. Children therefore need didactic tools that can help them understand the links between the various representations of fractions (Silver et al., 1983) to overcome these difficulties (Cramer et al., 2002). In addition, these didactic tools should be presented in a fun and empowering context, to motivate even the most reluctant children.

In terms of motivation, the use of games seems to be a good solution. Teachers and game companies have created a large variety of math games, especially to learn multiplications and fractions, such as those found 
on Math Games ${ }^{1}$, Matheros ${ }^{2}$, Educational Apps ${ }^{3}$, Fractions Game ${ }^{4}$ or Cat's Family ${ }^{5}$. In France, one of these games, called the Potion Workshop, is now used by more than 2000 schools.

In the next section, we will present this game and identify its limits. In the third section, we present how we designed a digital extension with Mixed Reality (MR) to overcome these limitations, in close collaboration with the mathematic didacticians who created the game and teachers that use it. This design methodology allowed us to create a truly original method for teaching fractions that is only possible with MR. In the fourth section, we show that, to our knowledge, this method is currently not used in any other application. We conclude with a discussion on the limitations of our design method and the description of the upcoming experimentations in class.

\section{The Potion Workshop: a Board Game for Learning Fractions}

As discussed in the introduction, Math, and especially fractions are known to cause demotivation and anxiety (Chen, 2019). Disguising the activities as non-mathematical and using game mechanics have shown good results, especially for girls (Hung et al., 2014). The game Potion Workshop (Atelier des potions ${ }^{6}$ ), for example, has proven to be very efficient (Pelay, 2019). This game was developed by researchers and teachers of the Plaisir Maths association, and is based on the results of N. Pelay's PhD thesis in didactics (Pelay, 2011). He showed that playing is not only a source of motivation for learning, but can also support learning itself with the concept of didactic and ludic contract. After two years of research and development, this game is now being adopted throughout the educational community.
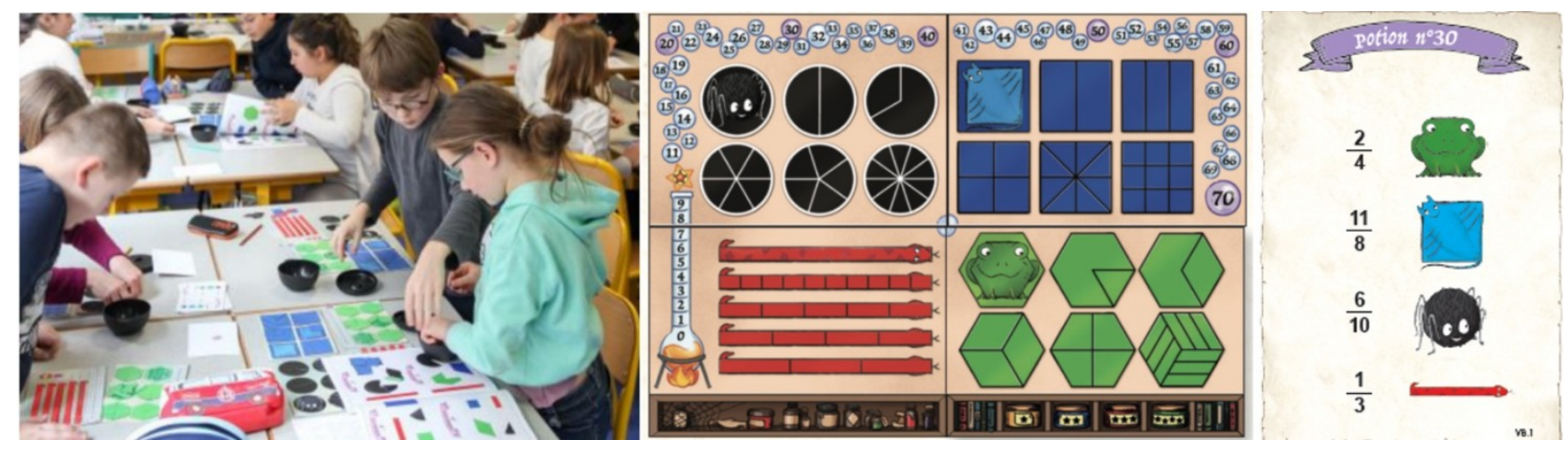

Figure 1. Children playing the Potion Workshop, the game board and the potion card $\mathbf{n}^{\circ} 30$

The children impersonate sorcerer apprentices who are leaning how to make magical potions. Each potion is described, on a card, with a set of fractions. As depicted in Figure 1, the four ingredients (spiders, rays, snakes and frogs) are pre-cut in different size portions (i.e. entire unit, halves, thirds, fourths...). The players need to find the right pieces and place them in the cauldron. Before placing the top on the cauldron, they decide how many stars they want to bet (1 to 4). If the answer is correct, they win the number of stars they bet and if the answer is incorrect, they lose them. The goal of the game is to have more stars than the other team, after preparing 10 potions. The players validate their own potions by placing the pieces of ingredients on shapes drawn in the answer key grimoire. If the potion is correct, the pieces cover the entire shape exactly, without going over the lines or leaving a visible section. The potions are classified in categories that introduce the key notions that need to be mastered. The teachers can therefore preselect the category they

\footnotetext{
1 https://www.jeuxmaths.fr/

2 https://matheros.fr/

3 https://www.logicieleducatif.fr/college/math/fractions-decimales.php

$4 \underline{\text { https://www.bsm-jeux.com/product/fractions }}$

5 http://france.catsfamily.net/

6 https://www.atelier-potions.fr/
} 
want students to work on. For instance, with the card $n^{\circ} 30$, children are experimenting the concept of a fraction greater than one.

The teachers who use the Potion Workshop are satisfied with the results. However, in classes with more than 25 students, it is very difficult for teachers to provide sufficient individual assistance and feedback. Our initial idea was therefore to provide a MR application that could recognize the game pieces used by the children and provide individual feedback and corrections. In the next section, we describe how this objective completely changed after a few collaborative design sessions with teachers. Our design-based research revealed a much more innovative and meaningful way of using MR!

\section{Collaborative Design of a Digital Extensions of the Board Game}

3.1.1. How to design a meaningful digital extension?

Even though it is the trend, digitalizing educational activities is not always a good idea. For example, one of the pedagogical advantages of the Potion Workshop comes from manipulating the objects and correcting your own exercises by overlying the pieces of ingredients on the answer key grimoire. The manipulation of objects creates engagement and the overlaying helps to grasp the concept of fraction equivalences. On the other hand, digital applications have the advantage of providing personalized feedback and showing infinite patience when it comes to explaining concepts repeatedly. They can therefore be of great assistance to teachers who have to deal with large heterogeneous classes (Zorrilla \& Álvarez, 2008).

Mixed Reality is a good compromise, as it offers all the advantages of a digital application, while still allowing learners to manipulate real objects, which is very important for learning, especially for children (Chandler \& Tricot, 2015; Liou et al., 2017). MR also has the capacity of providing contextual feedback directly on the manipulated objects or combining then with virtual 3D objects. In addition, MR is already successfully used for teaching fractions (Kazanidis et al., 2018; Palaigeorgiou et al., 2018; Radu et al., 2016). These applications are capable of displaying the manipulated objects' value and calculating their sum automatically to validate the exercises. Finally, MR has proven its capacity to diminish student's anxiety, in particular when studying math (Chen, 2019). However, even though MR offers many advantages, several studies highlight it's potential negative impacts on learning (Cheng, 2018) and the fact that setting up the material can add a layer of complexity for teachers and students, who will then be reluctant to accept it (Lin et al., 2011). Furthermore, none of the proposed solutions aims to exploit MR to link different representations of fractions (parts of an object and rational numbers placed on a number line).

It therefore seems paramount to collaborate with teachers, their students and, in our case, experts in math didactics, in order to design an application that has a positive impact on learning and that teachers can use in a normal class setting. We therefore followed the design-Based Research method (Carroll, 1996). This method was developed to address several central issues of Technology Enhanced Learning such as the need to find solutions with the end-users (teachers and students) and the need to study learning phenomena in the real world rather than in a laboratory (Collins et al., 2004). Design-Based Research implies several iterative cycles of collaborative design sessions with the end-users and the development of several porotypes. This method offers general guidelines that need to be adapted to the research objectives and context. In the next section, we present the way we adapted it for designing a MR application, with teachers and students who had never heard of MR before. First, we present how the end-users were gradually implicated in the design and testing of the porotypes. We then present the significant milestones that marked each cycle and led to the final design of the Magic Cauldron.

\subsubsection{Gradually implicating end-users in the design of a Mixed Reality application}

The design of an original Serious Game, such and the Magic Cauldron, requires the close collaboration of at least one expert in math, one expert in games and one developer (Marfisi-Schottman et al., 2010). As depicted in Figure 2, the team therefore initially started the first cycle with $\mathrm{P}$, the math didactician who designed the Potion Workshop, M, an expert in Serious Games design and T, an experienced developer with skills in MR. 
Just one month after, for the second cycle, the team welcomed G and O, two other experts in Serious Games and math didactics, but most importantly $\mathrm{R}$, an experienced math teacher, willing to participate in several design sessions and test the application with her class. We also recruited $\mathrm{Z}$ and $\mathrm{D}$, two math teachers willing to test and give detailed feedback on the prototypes.

For the third iteration, we recruited a graphic designer to improve the interface of the application and the game material but also to create an atmosphere and characters that are coherent with the Potion Workshop. We then implicated D and R's students to get their insight on the MR interactions and the story. At this point, we also implicated $\mathrm{H}$, a new teacher, who had never seen the application, to get a fresh perspective.

Finally, the fourth iteration, which has not yet been carried out, will involve five teachers and their classes for a large-scale experimentation: $\mathrm{Z}, \mathrm{H}$ and their students who have never tried the application, in addition to three other teachers and their students, completely new to the project.
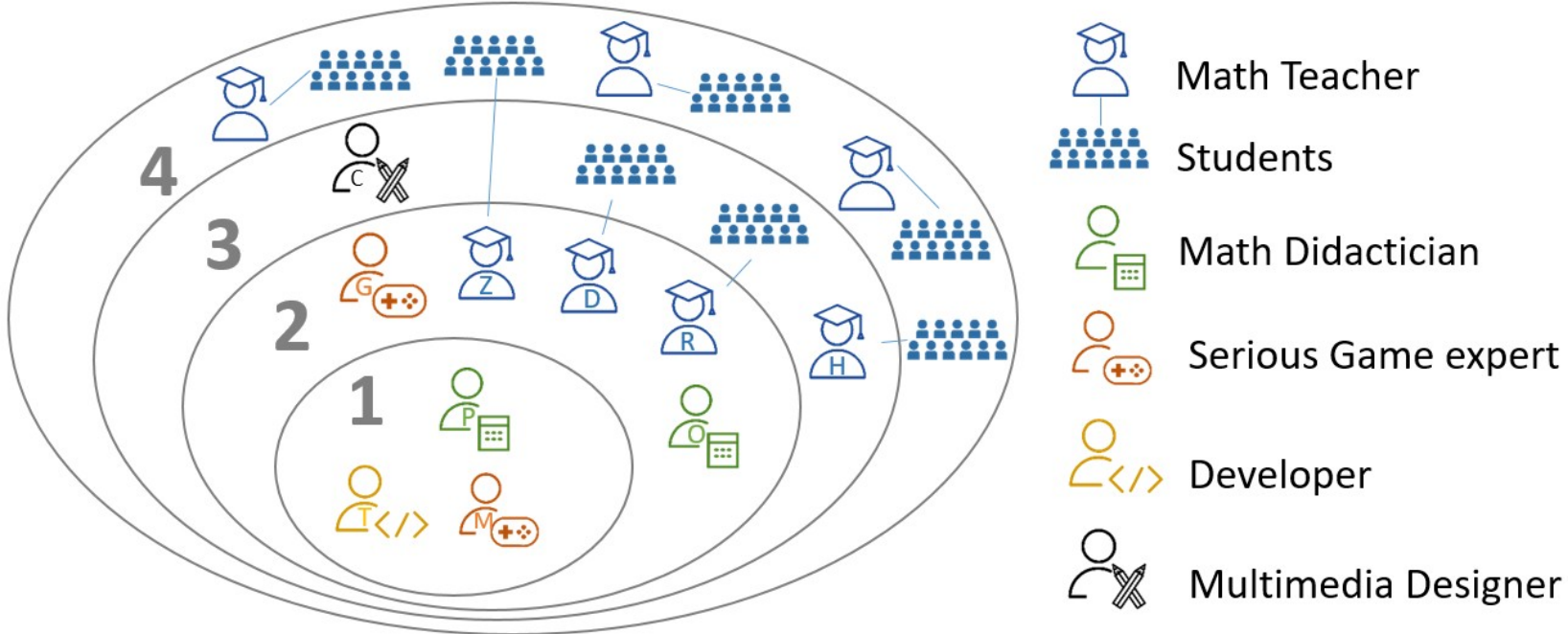

Figure 2. Gradual implication of the end-users in the four design cycles

This organization, depicted in Figure 2, insures a user-centered design. For practical reasons, only one teacher participated in the design sessions (with two math didacticians, two serious game experts and one developer) but the ideas developed during each of these sessions were put to the test, with several other teachers, some of which were completely new to the project. We also implicated the students, as soon as possible: once the graphic designer had improved the interface of the application. Finally, the large-scale experimentations, that aims at measuring the impact of the Magic Cauldron on learning, involves students who have not participated in the design nor tested the application, so as to insure they are as representative as possible of other middle schools students.

\subsubsection{Iterative design process for the design of a Mixed Reality application}

As depicted in Figure 3, the Magic Cauldron was created through four iterative cycles. Except for the very first, each of these cycles started with a design session with a team of two math didacticiens, one teacher, two serious game experts and one developer. These sessions usually last for 3 to 4 hours followed by several meetings to clarify specifics aspects of the design. The developer then programs a prototype that covers the ideas generated during this design session. The development of these prototypes are essential because they force the team to clarify their ideas and provide detailed mockup models and specifications. It also forces the team to identify the most promising ideas, knowing that the developer will not have time to develop all of them. The prototypes were also a very good way of involving teachers and children in the project. Testing an application is always more engaging and generates much more feedback then a descriptive document or presentation, especially when it comes to MR, a type of interactions they have never experienced. Finally, the prototype is the main object of attention during the next design session. With the teachers' and students' 
feedback in mind, the team tests this prototype to identity the functionalities that will be redesigned, enhanced or abandoned during the next cycle.

In the case of the Magic Cauldron, the manipulation of the MR prototypes by the teacher, during the design sessions, was clearly the key to generating original and meaningful ideas. For example, during the first design session, we had initially planned to use MR to provide automatic validation and custom feedback. We therefore developed a prototype that recognized the game pieces and could show their value. When the teacher tested the prototype, she spotted a completely different and original way of using MR that will undoubtedly be much more meaningful. She explained that children did not really need any help or extra incentive to work on fractions with the Potion Workshop or even on the exercises that she gives them in class, related to identifying a fraction as a portion an object. According to her, the breaking point is when she starts presenting fractions as rational numbers on a number line: "Children love working on fractions before. They assimilate it to coloring. It is when you get to the number line that things go wrong. Some kids just don't get it, even though they understood before!". The math didacticians confirmed this difficulty. One of the aspects that make fractions so hard to understand is the use of different representations (Silver et al., 1983). Behr \& Post (1993) identify six different representations: partitions of a whole, rational numbers, operators, ratio, decimals and measurement. Most importantly, none of the exercises in the official schoolbooks shows the relationship between these representations. The children therefore have a hard time making the link and are not capable of reusing the knowledge acquired before, with another representation. MR seems like the perfect medium to bridge this gap since it can simultaneously show several dynamic representations of a same fraction. At this point, our objective radically changed and we focused on finding MR activities that could help children understand the link between factions as partitions of a whole and fractions as rational numbers: the first obstacle encountered by children with fractions.

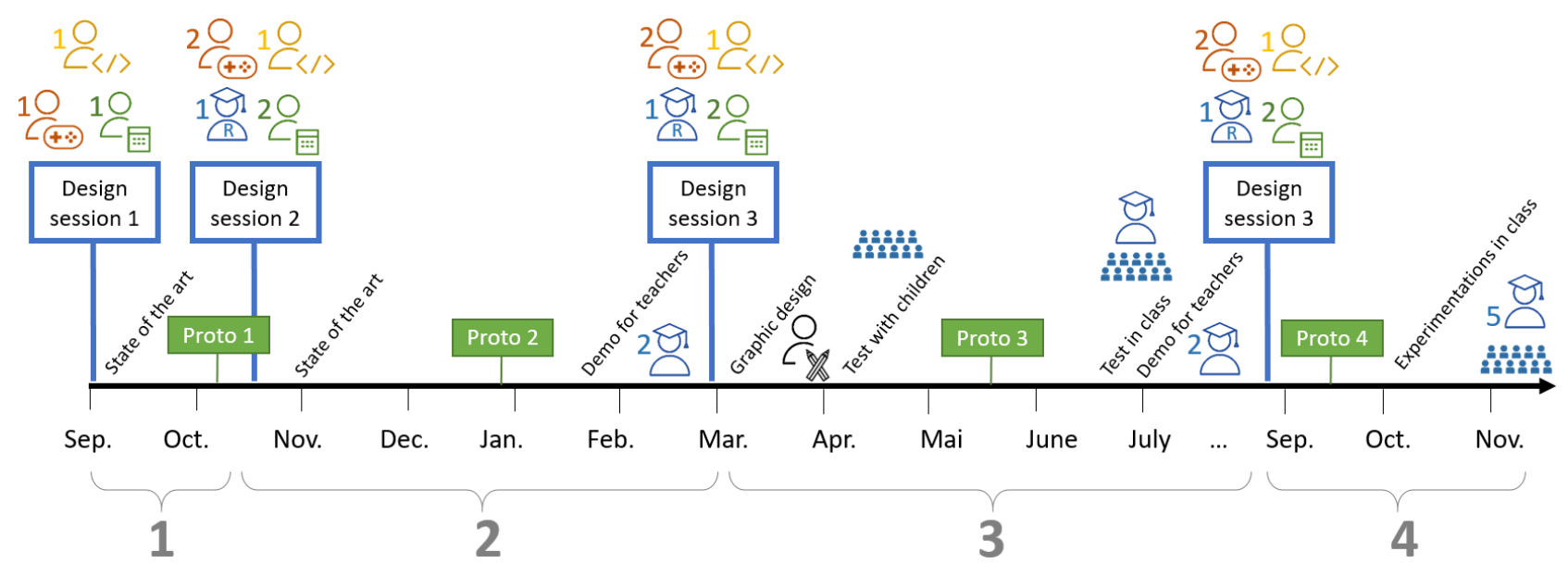

Figure 3. Iterative cycles of design sessions and prototype development

The second state of art on the representations of fraction (November), the tests with the other teachers (February) and the third design session confirmed that we were perusing in the right direction. The team then focused on creating various types of activities and imagining a game scenario around them, with the help of the teachers and their students. In April, 8 volunteer children tested the game in school. At that point, it only had the mathematical activities, without the storyline. We filmed them while they were testing the application and conducted semi-open interview with them afterwards, to know what they thought of the MR interactions. Thanks to these test sessions, we confirmed that MR sparks the interest of children and motivates them to take part in the activities. We were also able to improve the interface to make it more intuitive. In Mai, 4 volunteer children were consulted on the choice of the game characters, the game scenario and the dialogues in the games. We provided them with descriptions of each character, along with a video of the character in movement and the full game scenario. With the help of an adult (usually one of the parents), we collected their opinions for each of these items. Following their feedback, we replaced the 
characters they considered "too childish" and developed the background story of the two main characters, to give them more depth. We also changed more than $30 \%$ of the vocabulary for explaining the activities and almost rewrote the entire dialogues with the characters' personalities in mind, to make them sound livelier. We solicited the help of a professional storywriter for this last part.

We are currently testing the application in class and will present the game to two other teachers before the end of the school year (July 2021). Their feedback will allow us to prepare the last design cycle and experimentations with five teachers and their students in October or November 2021.

The co-designed activities and the game scenario, as they are at the end of cycle 3 , are presented in the next section.

\section{The Magic Cauldron: a Mixed Reality Extension to the Potion Workshop}

As explained in the previous section, our objective is to help children progressively understand that fractions are rational numbers, without creating a seizure with the way they are used to seeing fractions, i.e. as partitions of an object. Our idea is therefore to create a set of activities, in which the children have to find the equivalences between the two representations: object parts for the partition paradigm and a cursor on a number line for the rational number paradigm. For the object parts, we chose to use the game pieces of the Potion Workshop, since this game has proven to be effective and the children are used to manipulating them. Figure 4 shows the material for the last Magic Cauldron prototype, tested with a group of students in March 2021. We are currently redesigning the MR markers to fit the original shapes of the game pieces perfectly. Our first state of the art (Touel et al., 2020) and the discussions with teachers revealed that tablets were the type of hardware they could provide themselves with and set up with the least constraints. We also opted for a support arm that holds the tablet approximately $15 \mathrm{~cm}$ above the table to free the children hands. It is also possible to create a low cost support with boxes.
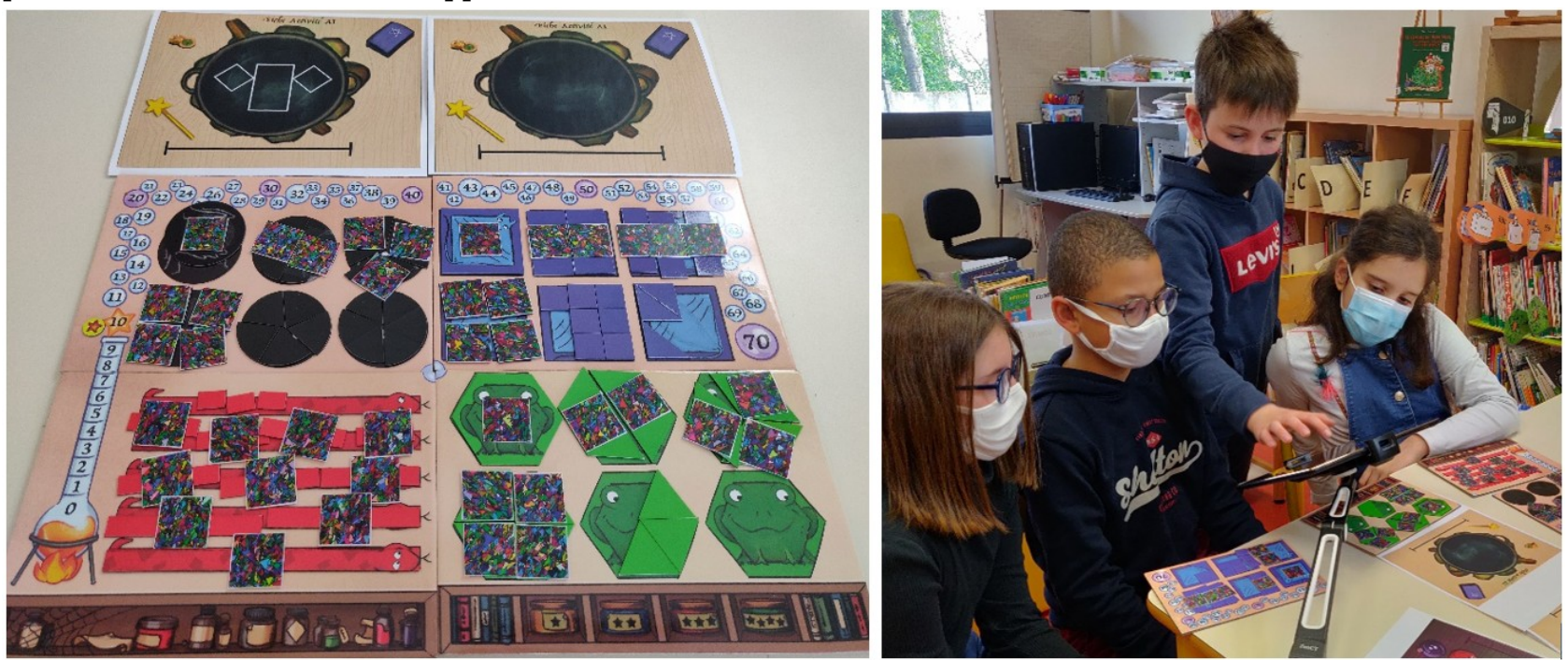

\section{Figure 4. Game material for the Magic Cauldron}

\subsection{The Mixed Reality Activities}

Through a game scenario, the Magic Cauldron offers four types of activities that will help children grasp fractions as rational numbers, by seeing their representation on a number line and simultaneously as parts of an object: the representation they have been using for more than a year.

\subsubsection{Recipe type activity}

In order the help the children see the connection between the game pieces and the value shown on the number line, we designed this warm-up activity (Figure 5, left). The objective for the child is to find and put the right ingredients (partition of objects) in the cauldron. As soon as the piece is placed in the cauldron, a cursor appear on the number line in Augmented Reality (AR). This line is intentionally of the same color as 
the ingredients and appears with puffs of smoke to attract the child's attention. The cursor (and the colored line) moves up and down the number line when the child adds or removes ingredients from the cauldron.

\subsubsection{Type 1 activity}

The objective of the type 1 activity is to represent a fraction on the number line by placing the cursor in the right place (Figure 5). The children can use the game pieces (that they already know), to make the equivalent line appear on the number line bellow. The child can then simply move the cursor (yellow) to the end of this line. The exercises become gradually more and more difficult with fractions greater that one.

\subsubsection{Type 2 activity}

The type 2 activity follows the same principal as type 1: the children need to place the cursor (yellow) in the right place on the number line. However, this time, they cannot help themselves by placing ingredients in the cauldron. Instead, they can divide the line in 1 to 10 sections (Figure 5). Some of the options can be disabled to make the exercise harder. For example, the child needs to place $3 / 4$ of ray but the option to divide in 4 is not available. When the child moves the cursor, the applications shows, in AR, the shapes of the ingredients in the cauldron. These ingredients have the same shape and size as the real ingredients, in order to facilitate the comparison. Here again, the exercises become gradually harder with fractions greater than one and disabled options.

\subsubsection{Type 3 activity}

The last type of activity, type 3, consists in finding and placing the right ingredients in the cauldron to match the value indicated by the cursor on the number line (Figure 5).. Once again, the exercise becomes more difficult with fractions greater than one and separations that do not match the fraction divider.
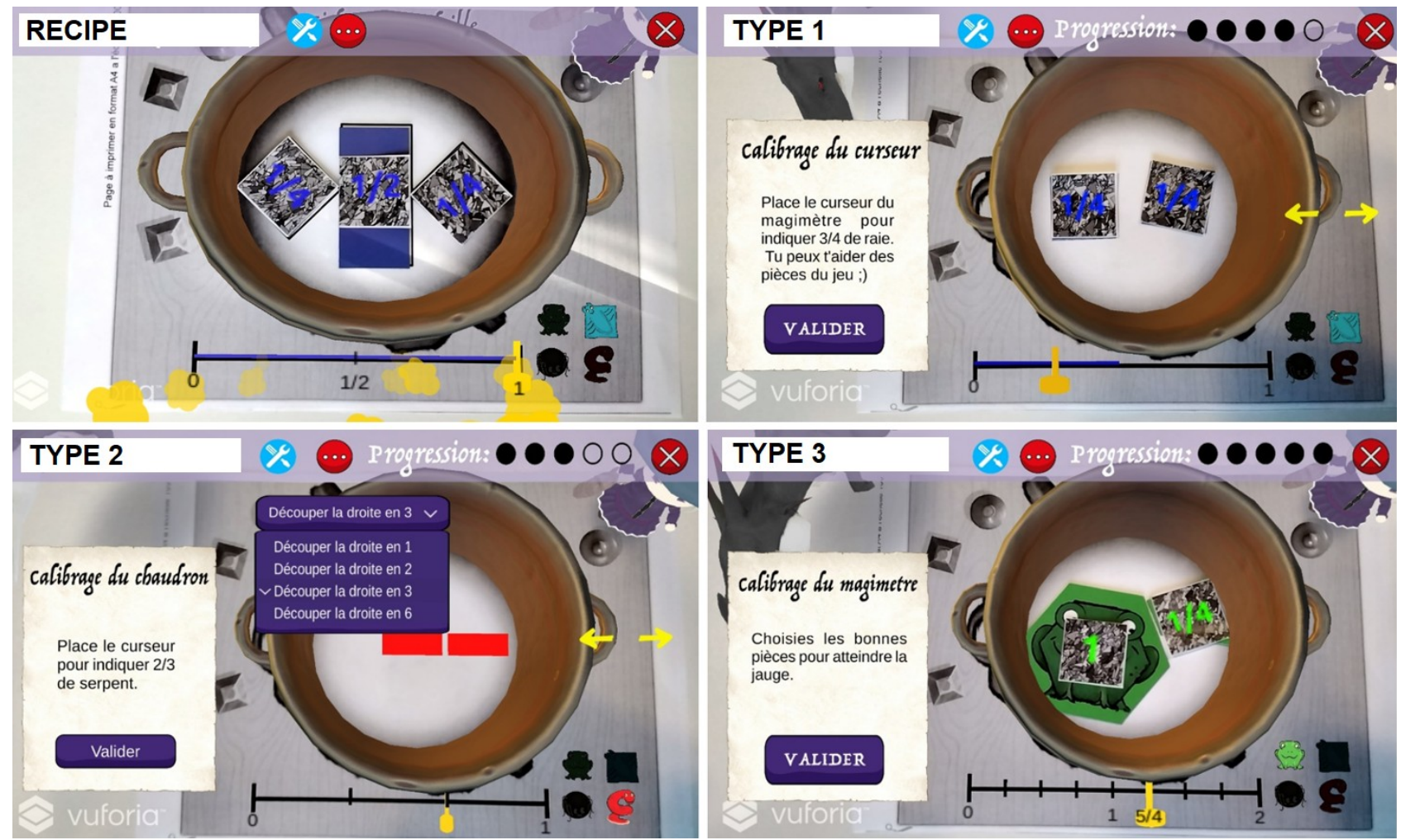

Figure 5. Four types of mathematical activities in the Magic Cauldron game 


\subsection{Game scenario}

After the tests with three teachers, we built a game scenario around these activities that was coherent with the Potion Workshop. The teachers also identified the order in which the activities should be done (recipe, type 1, type 2 and then type 3) and gave us the exact wording and fractions to create six exercises of each type. The idea of using a cauldron was straightforward given the imaginary universe built around the Potion Workshop and the fact that we wanted the children to place the pieces in a specific place (so the tablet could recognize them). We also developed the concept of the Magimeter for the number line. The magimeter is connected to the cauldron and its cursor shows the sum of the ingredients placed in the cauldron and their type (four lights on the right of the magimeter). We are currently working of its visual identity so that this object can be used in class for other activities, as suggested by the teachers.

The game scenario is built around recreating the connection between the cauldron and its magimeter. First, the children discover the cauldron and its guardian: Ekko the nice ghost. Ekko is thrilled to meet someone who seems to be able to use the cauldron and teaches the children how to create several animals (bird, bee, cat, and dog) with the recipe type activities. The nasty devil Arkan, the owner of the cauldron who never managed to use it, then appears and casts a freezing spell that blocks the magimeter's cursor. If he cannot use the cauldron then no one will! The children will have to complete several activities of type $\mathbf{1}$ to lift this spell. But Arkan comes back and casts another, more powerful spell that freezes magimeter's cursor and the cauldron. This time, the children have to complete activities of type 2 to lift the spell. On last time, Arkan comes back, and desynchronizes the entire magimeter! The children therefore have to complete activities of type 3. At the end, to stop Arkan from casting another spell, the children create a devilish creature to keep him company with one last recipe type activity.

Now that we have detailed the design process of the Magic Cauldron and the types of activities that we codesigned, we will present a short state of the art to show that these activities are original.

\section{State of the art}

Several MR applications were designed to teach fractions. As one could expect, most of these applications offer activities to understand the fraction as rational numbers, on a number line, since this is clearly the one of the main difficulties in learning fractions.

The marathon game of fractions (Palaigeorgiou et al., 2018), for example, offers a very rich scenario featuring several runners interrupted in their $2 \mathrm{~km}$ race, due to rain. The students must place the runners back where they stopped, on a number line. Their position is given as a fraction relative to the finish point (e.g. $2 / 3$ of the finish), the position of other runners or elements of the scene. Students can measure the size between two objects by resize and moving a MR number line. The MR also automatically validates the position of the runners.

The village game (Kazanidis et al., 2018) also offers a playful scenario to manipulate fractions on a number line. The game scenario features a child visiting his grandparents in their partially destroyed village. Using two virtual characters, the player's goal is to repair the infrastructure of the village (e.g. the pipe, the bridge represented by legos), by measuring the damaged part with the number line. Players can adjust the size, numerator and denominator of this line by manipulating screwdrivers and knobs. The game automatically detects if the damaged part of the infrastructure is correctly measured.

Finally, the Ready to Learn initiative [19] created a MR application to introduce the concept of number lines to children aged 6 to 9. The children place real objects on a line and the application automatically measures the position of these objects and displays it as a fraction. Students can change the denominator of the fraction, and the app automatically updates the numerator.

It is also possible to find MR applications that represent fractions as parts of an object. This is for example the case of the Math anxiety (Chen, 2019) application, in which the students have to choose the right piece of cake that corresponds to a fraction.

To our knowledge, no application combines two different representations of fractions, like the activities designed for the Magic Cauldron. We can therefore claim that the design-based research method we used 
allowed us to create a truly original and innovative way of teaching fractions that is now integrated into the Magic Cauldron.

\section{Conclusion and perspectives}

Learning fractions is one of the hardest cognitive challenges a child needs to face in middle school. The complexity of fractions is in part due to the different representations used in school. Fractions are first represented as parts of an object (e.g. $1 / 4$ of a cake) and, after one or two years, they are presented as rational numbers, placed on a number line. There is no transition between these representations and children are often incapable of reusing the notions of fractions acquired before. In this article, we propose the Magic Cauldron, a Mixed Reality (MR) application to bridge this gap. Our idea is to create a set of activities, in which the children have to find the equivalences between two representations: object parts and cursor on a number line. MR is the perfect means to create this type of activities since it is capable of recognizing the object parts that the children are used to manipulating and simultaneously showing their representation on a number line. This principal of simultaneously showing an object in two different representations could be used is countless other domains to help learners gradually get used to a new, more complex representation of a concept. The original idea for using MR and teaching fractions emerged thanks to the Design-Based Research method we followed. It gradually implicated teachers and their students into a team of mathematics didacticians, serious game experts and developers. The MR activities and the game scenario were progressively put together through three cycles of collaborative design and three prototypes. The way the Magic Cauldron application was designed ensures that it corresponds to a real need and meets the expectations of teachers and students.

The main limitation of this method it the fact that it is very time consuming. The multiple design cycles and the developments of several porotypes took more than a year. The necessary implication of end-users also complicates and slows down the project, especially with the additional limitations (travelling and school schedules) related to the COVID pandemic. In addition, the number of necessary cycles to create a truly satisfying application is unknown so it is impossible to provide a deadline for the end of the project, which is not compatible with most funding. However, we believe this method is relevant, especially when it comes to designing applications that provide innovative Human-Computer Interactions such as MR. This method guarantees the fact that the application will benefit to the end-user and, in terms of research, it is an effective way to discover meaningful and original ways of using these interactions for specific fields of expertise.

In the upcoming year, we wish to measure the added educational value of this applications and its new teaching method through several experimentations. The first experimentation, with one pilot teacher and her class, will take place in July 2021. The class will be separated into two groups. One will use the Magic Cauldron while the other will follow a classic lesson on fractions. We will compare the difference in learning outcome between the two groups with pre and post tests. We will also film the groups and ask the students and the teachers to fill out questionnaires to determine if the Magic Cauldron enhanced the students' autonomy and motivation. We have also planned several experimentations during the next school year with five teachers and their classes. They will test a new version of the Magic Cauldron, that integrates personalized help, and another version of the Magic Cauldron without MR, to determine if it is the game activities or the MR interactions that have an impact on learning, motivation and autonomy.

\section{Acknowledgments}

We would like to thank Anaïs RICHART, Hélène HARDY, Aurélie DERENNE, Amèle ZOUARI and their students for their participation in the project.

\section{References}

Behr, M., \& Post, T. R. (1993). Rational numbers: Toward a semantic analysis- -Emphasis on the Operator Construct: An Integration of Research. Rational Numbers: An Integration of Research, 13-47.

Carroll, J. M. (1996). Encountering Others: Reciprocal Openings in Participatory Design and User-Centered Design. Human-Computer Interaction, 11(3), 285-290. doi:10.1207/s15327051hci1103_5 
Chandler, P., \& Tricot, A. (2015). Mind Your Body: The Essential Role of Body Movements in Children's Learning. Educational Psychology Review, 27(3), 365-370. doi:10.1007/s10648-015-9333-3

Chen, Y.-C. (2019). Effect of Mobile Augmented Reality on Learning Performance, Motivation, and Math Anxiety in a Math Course. Journal of Educational Computing Research, 57, 1695-1722. doi:10.1177/0735633119854036

Cheng, K.-H. (2018). Surveying Students' Conceptions of Learning Science by Augmented Reality and their Scientific Epistemic Beliefs. Eurasia Journal of Mathematics, Science and Technology Education, 14(4), 1147-1159. doi:10.29333/ejmste/81811

Collins, A., Joseph, D., \& Bielaczyc, K. (2004). Design Research: Theoretical and Methodological Issues. Journal of the Learning Sciences, 13(1), 15-42. doi :10.1207/s15327809jls1301_2

Cramer, K., Post, T., \& delMas, R. (2002). Initial Fraction Learning by Fourth- and Fifth-Grade Students: A Comparison of the Effects of Using Commercial Curricula with the Effects of Using the Rational Number Project Curriculum. Journal for Research in Mathematics Education, 33, 111. doi:10.2307/749646

Gunderson, E. A., Hamdan, N., Hildebrand, L., \& Bartek, V. (2019). Number line unidimensionality is a critical feature for promoting fraction magnitude concepts. Journal of Experimental Child Psychology, 187, 104657. doi:10.1016/j.jecp.2019.06.010

Hung, C.-M., Huang, I., \& Hwang, G.-J. (2014). Effects of digital game-based learning on students' selfefficacy, motivation, anxiety, and achievements in learning mathematics. Journal of Computers in Education, 1(2), 151-166. Doi:10.1007/s40692-014-0008-8

I. Radu, \& al. (2016). Discovering educational augmented reality math applications by prototyping with elementary-school teachers. 2016 IEEE Virtual Reality (VR), 271-272. doi:10.1109/VR.2016.7504758

Kazanidis, I., Palaigeorgiou, G., \& Bazinas, C. (2018). Dynamic interactive number lines for fraction learning in a mixed reality environment. Proceedings of the South-Eastern European Design Automation, Computer Engineering, Computer Networks and Society Media Conference, 1-5. doi :10.23919/SEEDA-CECNSM.2018.8544927

Lin, H.-C. K., Hsieh, M.-C., Wang, C.-H., Sie, Z.-Y., \& Chang, S.-H. (2011). Establishment and Usability Evaluation of an Interactive AR Learning System on Conservation of Fish. Turkish Online Journal of Educational Technology - TOJET, 10(4), 181-187.

Liou, H.-H., Yang, S. J. H., Chen, S. Y., \& Tarng, W. (2017). The Influences of the 2D Image-Based Augmented Reality and Virtual Reality on Student Learning. Journal of Educational Technology \& Society, 20(3), 110-121.

Marfisi-Schottman, I., George, S., \& Tarpin-Bernard, F. (2010). Tools and Methods for Efficiently Designing Serious Games. Proceedings of the European Conferences on Games Based Learning, ECGBL, 226234.

Palaigeorgiou, G., Tsolopani, X., Liakou, S., \& Lemonidis, C. (2018). Movable, resizable and dynamic number lines for fraction learning in a mixed reality environment. doi :10.1007/978-3-030-119355_12

Pelay, N. (2011). Jeu et apprentissages mathématiques: Élaboration du concept de contrat didactique et ludique en contexte d'animation scientifique [PhD Thesis, Université Claude Bernard - Lyon I]. https://tel.archives-ouvertes.fr/tel-00665076

Pelay, N. (2019). L'atelier des potions: Un jeu de société didactique et ludique pour apprendre les fractions. Revue de Mathematiques Pour l'école, 231(numéro spécial sur le jeu en mathématique), 6-11.

Perronnet, C. (2018). Les sciences, c'est pas pour moi: Genre, culture scientifique et construction de représentations différenciées des sciences chez les enfants de milieux populaires. Transverse, Genre et Culture, 37-54.

Radu, I., McCarthy, B., \& Kao, Y. (2016). Discovering educational augmented reality math applications by prototyping with elementary-school teachers. Proceedings of the IEEE Virtual Reality Conference, 271-272. doi:10.1109/VR.2016.7504758

Siegler, R., Duncan, G., Davis-Kean, P., Claessens, A., Engel, M., Susperreguy, M. I., \& Chen, M. (2012). Early Predictors of High School Mathematics Achievement. Psychological Science, 23, 691-697. doi:10.1177/0956797612440101

Silver, E., Behr, M., Post, T., \& Lesh, R. (1983). Rational number concepts (pp. 91-126).

Touel, S., Marfisi-Schottman, I., \& George, S. (2020). Analysis of Mixed Reality Tools for Learning Math in Primary and Secondary School. In I. Marfisi-Schottman, F. Bellotti, L. Hamon, \& R. Klemke (Eds.), 
Games and Learning Alliance (pp. 112-121). Springer International Publishing. doi:10.1007/978-3030-63464-3_11

Zorrilla, M. E., \& Álvarez, E. (2008). MATEP: Monitoring and Analysis Tool for E-Learning Platforms. Proccedings of the IEEE International Conference on Advanced Learning Technologies, 611-613. doi:10.1109/ICALT.2008.33 